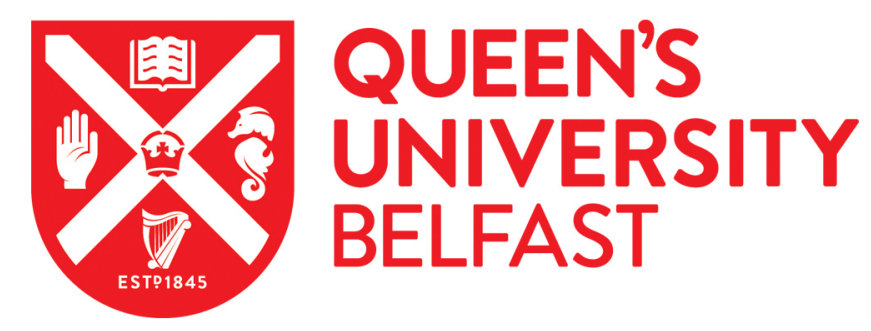

\title{
Association of ABCB1 and VEGFA gene polymorphisms with breast cancer susceptibility and prognosis
}

Madrid-Paredes, A., Casado-Combreras, M. A., Perez Ramirez, C., Segura-Perez, A. M., Chamorro-Santos, C., Vergara-Alcaide, E., Sanchez-Pozo, A., Calleja Hernandez, M. A., \& Cañadas-Garre, M. (2020). Association of ABCB1 and VEGFA gene polymorphisms with breast cancer susceptibility and prognosis. Pathology, research and practice, 216(4), [152860]. https://doi.org/10.1016/j.prp.2020.152860

Published in:

Pathology, research and practice

Document Version:

Peer reviewed version

Queen's University Belfast - Research Portal:

Link to publication record in Queen's University Belfast Research Portal

Publisher rights

Copyright 2020 Elsevier $\mathrm{GmbH}$.

This manuscript is distributed under a Creative Commons Attribution-NonCommercial-NoDerivs License

(https://creativecommons.org/licenses/by-nc-nd/4.0/), which permits distribution and reproduction for non-commercial purposes, provided the author and source are cited.

\section{General rights}

Copyright for the publications made accessible via the Queen's University Belfast Research Portal is retained by the author(s) and / or other copyright owners and it is a condition of accessing these publications that users recognise and abide by the legal requirements associated with these rights.

Take down policy

The Research Portal is Queen's institutional repository that provides access to Queen's research output. Every effort has been made to ensure that content in the Research Portal does not infringe any person's rights, or applicable UK laws. If you discover content in the Research Portal that you believe breaches copyright or violates any law, please contact openaccess@qub.ac.uk. 
INDEX

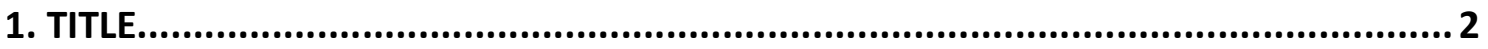

2. ABSTRACT

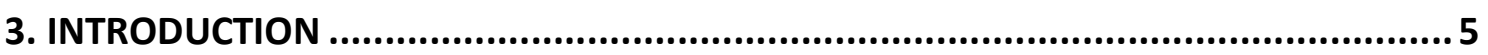

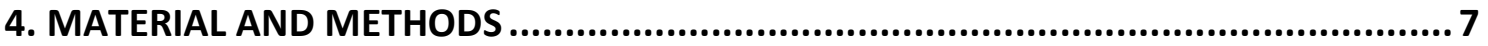

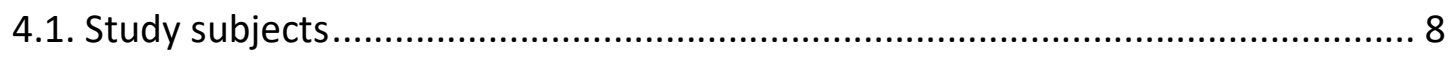

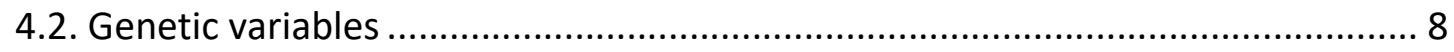

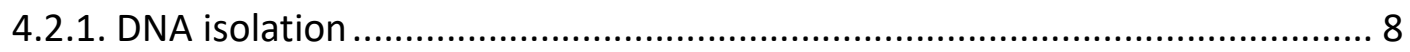

4.2.2. Detection of gene polymorphisms .................................................... 8

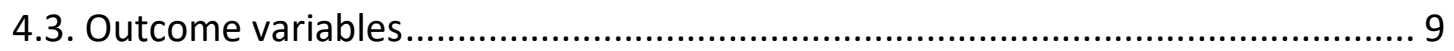

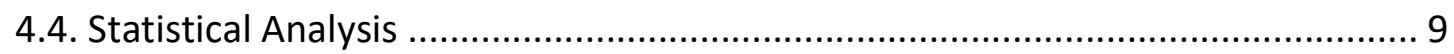

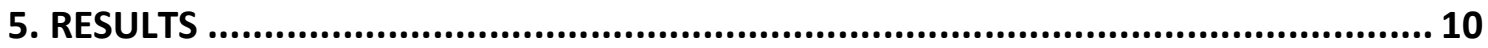

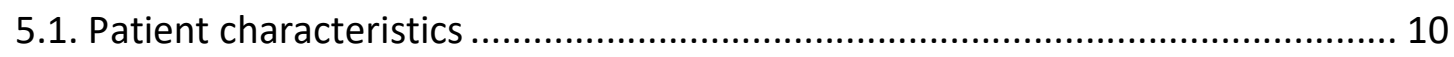

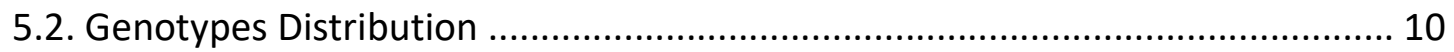

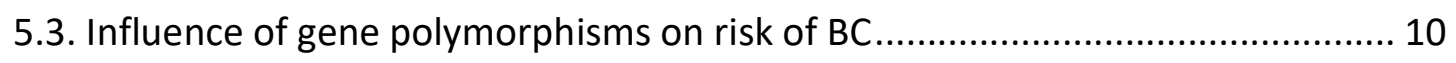

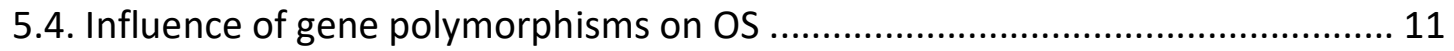

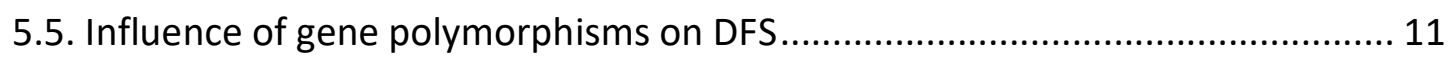

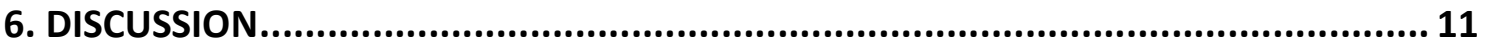

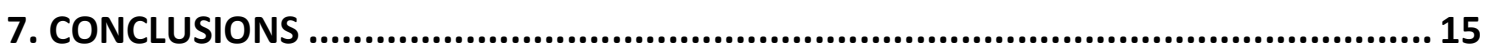

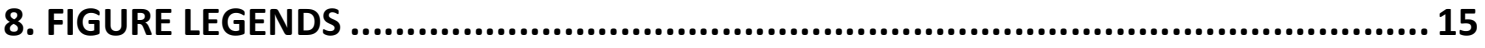

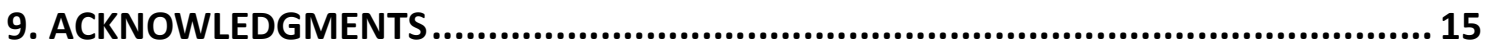

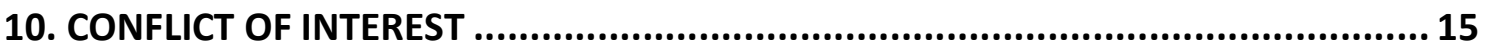

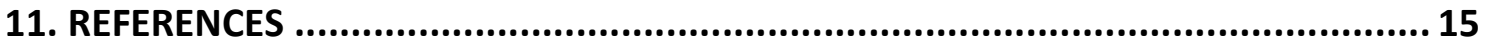




\section{TITLE}

\section{ASSOCIATION OF ABCB1 AND VEGFA GENE POLYMORPHISMS WITB BREAST CANCER}

SUSCEPTIBILITY AND PROGNOSIS

\section{RUNNING TITLE:}

\section{ABCB1 AND VEGFA POLYMORPHISMS IN BREAST CANCER}

\section{AUTHORS:}

Adela Madrid-Paredes ${ }^{1}$, Miguel Ángel Casado-Combreras ${ }^{1}$, Cristina Pérez Ramírez ${ }^{2}$, Ana María Segura-Pérez ${ }^{3}$, Clara Chamorro Santos ${ }^{3}$, Esther Vergara Alcaide ${ }^{3}$, Antonio Sánchez-Pozo², Miguel Ángel Calleja-Hernández², Marisa Cañadas-Garre ${ }^{5}$.

\section{Author for correspondence}

\section{Cristina Pérez Ramírez}

Pharmacy Service. Pharmacogenetics Unit

Hospital Universitario Virgen Macarena

Calle Dr. Fedriani, 3, 41009 Sevilla

Telephone: +34955008000

\section{Affiliations}

1. Pharmacy Service. Pharmacogenetics Unit Hospital Universitario Virgen de las Nieves Instituto de Investigación Biosanitaria de Granada Complejo Hospitalario Universitario de Granada Avda. Fuerzas Armadas, 2, 18071 Granada, Spain

Telephone: $\quad+34958020108$

Fax: $\quad+34901021804$

Telephone: $\quad+34958243838$

2. Pharmacy Service. Pharmacogenetics Unit Pharmacy Service. Pharmacogenetics Unit Hospital Universitario Virgen Macarena Calle Dr. Fedriani, 3, 41009 Sevilla Telephone: +34955008000

\section{Pathology Service}


UGC Anatomía Patológica

Instituto de Investigación Biosanitaria de Granada

Complejo Hospitalario Universitario de Granada

Avda. Fuerzas Armadas, 2

18014 Granada, Spain

Telephone: $\quad+34958020374$

4. Department of Biochemistry

Faculty of Pharmacy

University of Granada

Campus Universitario de Cartuja, s/n

18071 Granada, Spain

Telephone: $\quad+34958243827$

\section{Queen's University Belfast}

Centre for Public Health

Queen's University of Belfast

c/o University Floor, Level U, Room OU.023, Tower Block

Belfast City Hospital, Lisburn Road, Belfast, BT9 7AB

Telephone: +44 (0)2890976002

Fax: $+44(0) 2890235900$

Mails

Adela Madrid-Paredes

adelamadridparedes@gmail.com

Miguel Ángel Casado-Combreras

miguelangel.ccma@gmail.com

Cristina Pérez Ramírez

cperezramirez87@gmail.com

Ana María Segura-Pérez

anichu29@gmail.com

Clara Chamorro Santos

clarae.chamorro.sspa@juntadeandalucia.es

Esther Vergara Alcaide

mariae.vergara.sspa@juntadeandalucia.es

Antonio Sánchez-Pozo

sanchezpster@gmail.com

Miguel Ángel Calleja Hernández

mangel.calleja.sspa@juntadeandalucia.es

Marisa Cañadas-Garre

marisacgarre@gmail.com

\section{KEYWORDS}

SUSCEPTIBILITY 
PROGNOSIS

BREAST CANCER

POLYMORPHISMS

WORD COUNT (excluding references and figure legends):

Abstract: $\quad 279$ words

Main Text: 3332 words

\section{FUNDING}

The Hospital Universitario Virgen de las Nieves Biobank was supported by grants cofinanced by FEDER funds (EU) from the Instituto de Salud Carlos III (PT13/0010/0039).

\section{ABSTRACT}

Breast cancer $(\mathrm{BC})$ is the most common cause of cancer-related death in women worldwide. Several ABCB1 and VEGFA gene polymorphisms, such as ABCB1-G1199T/A (rs2229109), VEGFA -634 G>C (rs2010963), VEGFA 2578 C>A (rs699947) and VEGFA 7 C>T (rs25648) have been associated with risk of BC and clinical outcomes. The purpose of this study was to evaluate the association between these gene polymorphisms and $\mathrm{BC}$ risk and prognosis.

A retrospective case-control study was conducted, including 84 BC cases and 119 controls of Spanish (European, Caucasian) origin. ABCB1-G1199T/A (rs2229109), VEGFA -634 G>C (rs2010963), VEGFA 2578 C>A (rs699947) and VEGFA 7 C>T (rs25648) gene polymorphisms were analysed by TaqMan ${ }^{\circledR}$.

The genotypic logistic regression model adjusted by aged revealed no association with any of the polymorphisms and BC risk, although the C-allele of VEGFA $2578 \mathrm{C}>\mathrm{A}$ showed a trend to higher $B C$ risk in the allelic and recessive models $(p=0.055$ and 0.054 , respectively). There was no influence of these gene polymorphisms on overall survival (OS). The univariate Cox model showed that carriers of the A-allele for VEGFA 2578 C >A tended to have longer OS compared to CC patients (CC vs A-allele Hazard ratio (HR): 2.08; $\left.\mathrm{Cl}_{95 \%}=0.96-4.49 ; \mathrm{p}=0.0587\right)$. There was no association between the gene polymorphisms analysed and disease-free survival (DFS). The univariate Cox model showed a trend toward a longer DFS in patients carrying ABCB1-G1199T/A GG genotype compared to those with A-allele (GG vs A-allele HR: 0.43; $\mathrm{Cl}_{95 \%}=0.18-1.03 ; \mathrm{p}=0.0612$ ). 
No influence of ABCB1-G1199T/A (rs2229109), VEGFA -634 G>C (rs2010963), VEGFA 2578 C>A (rs699947) and VEGFA 7 C>T (rs25648) gene polymorphisms on risk of developing $B C$ was found in our study. There was no association between the polymorphisms studied and DFS and OS.

\section{INTRODUCTION}

Breast cancer $(\mathrm{BC})$ is the most common cause of cancer-related death in women worldwide (1). Although the etiology of this illness is not completely understood, it is known that genetic components have an important contribution to the development of the disease (2). In the recent decades, many studies have explored the association between some genetic biomarkers potentially involved in BC susceptibility, such as the ATP-binding cassette, B1 ( $A B C B 1)$ and the vascular endothelial growth factor A (VEGFA) $(3,4)$.

The ABCB1 gene encodes the P-glycoprotein, which is an efflux pump for some antineoplastic agents, resulting in a mechanism of resistance to chemotherapy $(5,6)$. Three single nucleotide polymorphisms (SNPs), referred as C1236T (rs1128503), C3435T (rs1045642) and G2677T/A (rs2032582), are the most widely studied in ABCB1 (7). However, another polymorphism located in the ABCB1 gene (-G1199T/A or rs2229109) has not already been studied as a risk factor for BC. This polymorphism has been associated with colorectal cancer risk in a cohort of German women (11). The influence of this polymorphism on clinical outcomes has been reported in other malignancies with different results. Ninety patients with relapsed or refractory multiple myeloma treated with lenalidomide showed a trend towards an increased time to progression when carrying the ABCB1-G1199T/A A-variant (12). In ovarian cancer, while a shorter progression free survival (PFS) was shown in 525 patients treated with carboplatin and paclitaxel (13), no effect was observed in a cohort of 51 patients (14).

Angiogenesis is one of the mechanisms used by cancer cells to grow, invade and disseminate the disease $(15,16)$. The vascular endothelial growth factor A (VEGFA) is able to induce angiogenesis stimulating specifically the vascular endothelial cells and formation of new blood vessels (17). VEGFA is located in chromosome 6p21.3 and is highly polymorphic (18). Some VEGFA polymorphisms have been identified as potential 
breast cancer susceptibility gene polymorphisms, as -634 G>C (rs2010963), 2578 C>A (rs699947) and 7 C>T (rs25648) (19).

The VEGFA -634 G/C polymorphism is correlated with VEGFA protein expression levels (20). This polymorphism has not been associated with BC risk in several meta-analyses performed in Caucasians and Asians $(21,22)$ nor in Moroccan population (23). A significant association between VEGF -634 G-allele and decreased BC susceptibility was found in Asians, but not in Caucasians in a recent meta-analysis encompassing 9 studies (7262 cases and 7380 controls) (24). According to clinical outcomes, the -634CC genotype was a significant predictor of adverse prognosis compared to -634 G-allele disease free survival (DFS) in a study of 116 HER2-positive BC patients treated with trastuzumab (25). No effect of the VEGFA -634G/C polymorphism was observed on 5year survival in 446 Thai BC patients after univariate analysis. However, patients with the $-634 C / C$ genotype had lower DFS compared with the homozygotes for the G-allele (26).

A meta-analysis encompassing 7 studies (4572 cases/4652 controls) did not find association between the VEGFA 2578C/A polymorphism and susceptibility to BC in any of the genetic models tested either in the analysis by ethnicity (Asians and Caucasians) (27). Two studies were published after this meta-analysis. An increased risk of BC was observed in patients with VEGFA 2578 AA genotype and A-allele in 204 cases and 208 controls from North India (28). This effect of the A variant of VEGFA 2578 C/A as risk factor for BC was also observed in an Iranian study (250 cases/215 controls) (29). The role of VEGFA $2578 \mathrm{C} / \mathrm{A}$ polymorphism on DFS has been explored in a cohort of 890 Brazilian BC patients. The variant genotypes of VEGFA $2578(C A+A A)$ were significantly associated with shorter DFS among 309 patients treated with neoadjuvant chemotherapy followed by mastectomy, whereas it did not show any effect on DFS in the $581 \mathrm{BC}$ patients treated with curative surgery (30). Two studies performed in Caucasian and Asian BC patients found no significant results on DFS $(25,26,31)$ nor in OS (31).

The VEFGA 7C>T polymorphism has unsuccessfully been proposed as a candidate to predict BC risk both in Caucasian and Asian population $(32,28)$. The VEGFA -7C $>$ T CC genotype failed as independent prognostic factor in multivariate analysis in a study of 
116 HER2-positive BC patients treated with trastuzumab (25). However, it may influence OS, as shown in 328 Caucasian BC patients (32).

The present study aimed to explore an ABCB1 and VEGFA SNPs as potential biomarkers for BC risk and prognostic evaluation of clinical outcomes. Spanish (European, Caucasian) women diagnosed with BC were evaluated for the association between ABCB1 rs2229109 and VEGFA polymorphisms (634 G/C, 2578 C/A, 7 C>T) and their impact on BC risk, DFS and OS.

\section{MATERIAL AND METHODS}

A retrospective case-control study was conducted for the investigation of $\mathrm{BC}$ risk, and a cohort study for the sub-study of clinical outcomes in BC.

\subsection{Study subjects}

In total, 84 cases with a pathology-confirmed diagnosis of BC and 119 healthy female donors who had no history of any cancer diseases (controls) were enrolled in the casecontrol study. Patients' general characteristics and related risk factors were collected by reviewing clinical records, including: age, menarche age, BC background, cancer stage at diagnosis, nulliparity, menopause, tumour size, grade, hormonal receptors, ki67 antigen, nodal involvement, number of involved nodes, molecular subtype, histological type and trastuzumab treatment. This study was approved by the CHUG Ethics and Research Committee and was performed conform the declaration of Helsinki. The staging system used to classified tumours was based on the guidelines of the American Joint Committee on Cancer (AJCC) (33).

\subsection{Genetic variables}

\subsubsection{DNA isolation}

Samples were obtained from the Hospital Universitario Virgen de las Nieves Biobank, a part of the Sistema Sanitario Público de Andalucía Biobank (Expedient number \#37130103). Blood samples $\left(3 \mathrm{ml}\right.$ ) were collected in BD Vacutainer ${ }^{\circledR} \mathrm{K} 3 \mathrm{E}$ Plus Blood Collection Tubes. Five $7 \mu \mathrm{m}$-sections of formalin-fixed, paraffin-embedded tissue (BC tissue and adjacent normal breast tissue) were used to isolate DNA. The selection of the most representative areas was made by two experienced breast pathologists (CCS and 
EVA), and they were processed independently. Paraffin was removed by xylene-ethanol extraction before processing for DNA isolation.

DNA was extracted using QIAamp DNA Mini Kit (QiagenGmBH, Hilden, Germany) according to the manufacturer's instructions for DNA purification from blood or tissue and stored at $-40 \circ \mathrm{C}$.

\subsubsection{Detection of gene polymorphisms}

ABCB1-G1199T/A (rs2229109), VEGFA 634 G>C (rs2010963), VEGFA 2578 C>A (699947) and VEGFA 7 C >T (rs25648) gene polymorphisms were analysed by Real-Time PCR using TaqMan $^{\circledR}$ probes. Genotyping methodology was previously described (34).

\subsection{Outcome variables}

DFS was calculated as the time from cancer diagnosis to relapse, death or last known follow-up.

OS was measured from time from cancer diagnosis until final follow-up or death.

\subsection{Statistical Analysis}

Descriptive analysis was performed using R 3.3.1 (35). Quantitative data were expressed as the mean ( \pm standard deviation) for normally-distributed variables or medians and percentiles (25 and 75) for non-normal distribution variables. Normality was assessed by Shapiro-Wilks test. The t-Student test was applied for normally distributed variables, and non-parametric Wilcoxon test otherwise. Bivariant association for qualitative dichotomous variables was analysed with the Pearson's chi-square or Fisher's exact test. The permutation test was applied for multiple comparisons. Multivariate Cox proportional hazard regression model was used to obtain the adjusted HR and $95 \%$ confidence interval ( $\mathrm{Cl}_{95 \%}$ ) for potential prognostic factors for survival and progression. The Kaplan-Meier method and the log-rank test were used to analyze associations between survival and progression with demographic, clinical and genetic variables. Hardy-Weinberg equilibrium and pairwise haplotype frequencies were estimated, and Lewontin's D prime $\left(D^{\prime}\right)$ and the linkage disequilibrium coefficient $\left(r^{2}\right)$ were calculated. The bivariate association between $\mathrm{BC}$ risk and polymorphisms was assessed for multiple models (genotypic, additive, allelic, dominant and recessive), using the Pearson's chisquare and Fisher's exact test, and evaluated by OR and their corresponding $95 \% \mathrm{Cl}$. The 
models were defined as follows: allelic (D vs d), dominant ((DD, Dd) vs dd), recessive (DD vs $(D d, d d)$ ) and genotypic (DD vs Dd vs $d d$ ), being $D$ the minor allele and $d$ the major allele. Permutation analysis (EMP1) was used for multiple comparisons, that compares the observed statistic with 100,000 statistics obtained in permutations in the correspondent SNP. To control the family-wise error rate when testing multiple SNPS, the observed statistic was compared with the maximum of permuted statistics over all SNPs (EMP2). Unconditional multiple logistic regression models (genotypic, dominant and recessive) were considered to determine the influence of potential confounding variables on the risk of breast cancer. All tests were two-sided with a significant level of $p<0.05$, and were performed using the free, open-source whole genome association analysis toolset PLINK or R 3.3.1 $(35,36)$.

\section{RESULTS}

\subsection{Patient characteristics}

The study population comprised 84 Caucasian patients with HER2-positive BC who received trastuzumab treatment and 119 controls. The patients' clinical and demographic characteristics are summarized in Table 1. The mean age at diagnosis was $52 \pm 13$ years in cases and $65[59.5-75]$ years in controls. Six patients $(6 / 84 ; 7.1 \%)$ received neoadjuvant trastuzumab as first line and fifty patients $(50 / 84 ; 50.9 \%)$ as adjuvant treatment. Thirty-six $(36 / 84 ; 43.4 \%)$ patients presented nodal involvement and sixty patients $(60 / 84 ; 71.8 \%)$ were initially diagnosed with invasive ductal carcinoma. Thirtyeight patients $(38 / 83 ; 45.78 \%)$ had progesterone receptor (PR)-positive tumors and 48 patients $(48 / 83 ; 57.83 \%)$ had estrogen receptor (ER)-positive tumors. Forty-seven patients $(47 / 82 ; 57.3 \%)$ had a molecular subtype luminal HER2.

A longer DFS and OS was associated to trastuzumab treatment as first line (HR: 0.25; $\mathrm{Cl}_{95 \%}$ : 0.013-0.48; $\mathrm{p}<0.001$ ) and (HR: 0.21; $\mathrm{Cl}_{95 \%}$ : 0.09-0.47; $\mathrm{p}<0.001$ ), respectively (Tables S1 and S2).

Tumour grade was associated with DFS ( $p=0.0206$; Table S2). No other clinical and demographic characteristics were associated to DFS or OS (tables S1 and S2). 


\subsection{Genotypes Distribution}

All gene polymorphisms distributions were in Hardy-Weinberg equilibrium and were similar to those described in the International HapMap Project. No linkage disequilibrium was showed in any case.

\subsection{Influence of gene polymorphisms on risk of BC}

The bivariate analysis was performed in multiple models: genotypic, additive, allelic, dominant and recessive (Table 2).

The genotypic logistic regression model adjusted by age revealed no statistical association with any of the polymorphisms (Table 3). VEGFA 2578 C>A was the only gene polymorphism which showed a trend to higher risk of $B C$ in the allelic and recessive model but it was not statically significant. In particular, patients carrying the C-allele reported a trend to higher risk of $B C$ versus those with AA genotype $(p=0.054 ; O R=0.52$; $\left.\mathrm{Cl}_{95 \%}=0.24,1.06\right)$ or $\mathrm{A}$ allele $\left(\mathrm{p}=0.055 ; \mathrm{OR}=0.68 ; \mathrm{Cl}_{95 \%}=0.45,1.00\right)$. A logistic regression model adjusted by age and permutation analysis was used to further investigated the impact of VEGFA 2578 C>A gene polymorphism on risk of BC. No association was found in any of the analysis performed (Table 3 and 4). No other gene polymorphisms showed an association to $B C$ in any of the models tested (Table 2) but there was a trend to higher risk in patients carrying C-allele of VEGFA 2578 C >A in the allelic and recessive models ( $p$ value $=0.055$ and 0.054 , respectively) (Table 4 )

\subsection{Influence of gene polymorphisms on OS}

No gene polymorphisms showed influence on OS, although the univariate Cox model showed that CC carriers for VEGFA 2578 C >A tended to shorter OS compared to A-allele patients (CC vs A-allele HR: 2.08; $\mathrm{Cl}_{95 \%}=0.96-4.49 ; \mathrm{p}$ value=0.0587) (Table 5). The Kaplan Meier survival analysis is shown in Figures S1 and S2.

\subsection{Influence of gene polymorphisms on DFS}

There was no association between the gene polymorphisms analysed and DFS. The univariate Cox model showed a trend toward a longer DFS in patients carrying ABCB1G1199T/A GG genotype comparing with those with A-allele (GG vs A-allele HR: 0.43; $\mathrm{Cl}_{95 \%}=0.18-1.03 ; \mathrm{p}$ value $=0.0612$ ) (Table S3). Kaplan-Meier curve for DFS according to ABCB1-G1199T/A gene polymorphism is shown in Figure S3. 


\section{DISCUSSION}

It is thought that genetic components have an important role in the aetiology of $\mathrm{BC}$. Some genetic biomarkers referred as VEGFA 2578 C >A, $634 \mathrm{G}>\mathrm{C}$ and 7 C >T have been studied as potentially factors involved in BC susceptibility with conflicting results $(3,4)$. The ABCB1 G1199T/A polymorphism, only studied in other cancer types, is a novel variant to consider in $\mathrm{BC}$. These polymorphisms were determined in 84 cases of $\mathrm{BC}$ and 119 controls of South Spanish Caucasian origin.

The ABCB1-G1199T/A (rs2229109) polymorphism was not associated with BC risk in our study. There is only one study evaluating the association of this polymorphism and risk of cancer, but in a cohort of colorectal cancer patients (11). Our study is the first one performed in a BC population. The ABCB1-G1199T/A polymorphism was not associated with OS in our study (Table S3), but a trend toward a longer DFS was observed in patients carrying the ABCB1-G1199T/A GG genotype, compared with those with A-allele (GG vs A-allele HR: 0.43; $\mathrm{Cl}_{95 \%}=0.18-1.03 ; p$ value=0.0612) (Table S3, Figure S3). The influence of this polymorphism and survival outcomes in $\mathrm{BC}$ patients had not been studied yet. In our study, the VEGFA - $634 \mathrm{G} / \mathrm{C}$ was not associated with BC risk. This is in agreement with previous results in Moroccan population (23) and several meta-analyses $(21,22,24)$. The meta-analysis published by Ma et al. 2015 only found association of VEGFA -634 G/C polymorphism and $\mathrm{BC}$ risk in Asian patients (GG vs C-allele OR: $0.74 ; 95 \% \mathrm{Cl}$ : $0.62-0.87$; $\mathrm{p}<0.001)$. Hence, this association may not be extrapolated to the Caucasian population as in our study.

Regarding to clinical outcomes, the VEGFA -634CC genotype was a significant predictor of adverse prognosis compared to -634 G-allele in terms of DFS (CC vs G-allele HR:2.96; 95\% Cl: 1.33-6.59; $\mathrm{p}=0.008$ ) in a study of 116 HER2-positive BC patients treated with trastuzumab (25), and in a study of 446 Thai BC patients (CC vs GG HR: 3.05; 95\% Cl: 1.35-6.87; $p=0.007$ ) (26). We could not find association of VEGFA $-634 \mathrm{G} / \mathrm{C}$ polymorphism with DFS in our sub-cohort of BC patients. Despite the present study and the one published by Maae et al. 2012 (25) were performed in Caucasian HER2-positive $B C$ patients, different characteristics between the two populations may explain the discrepant results. Our cases are younger and with a higher proportion of patients undergoing an adjuvant treatment. The $93.1 \%$ of their patients had a ductal carcinoma, 
while only $72 \%$ of our patients presented this type of carcinoma. The axillary nodal involvement was also lower in our study (43.5\% vs $60 \%)$.

The VEGFA -634 G/C polymorphism was not associated to OS in our study, as reported in a Thai population (5-year OS; $p=0.490)(26)$.

We could not find influence of VEGFA $2578 \mathrm{C} / \mathrm{A}$ polymorphism on BC risk, although a trend to higher risk was shown in C-allele carriers in the allelic and recessive models ( $p$ value $=0.055$ and 0.054 , respectively) (Table 3). This lack of relevance on BC risk is in agreement with the results of a meta-analysis encompassing 7 studies (4572 cases/4652 controls), which showed no significant association between the VEGFA 2578C/A polymorphism and susceptibility to BC (AA vs CC OR: $1.03,95 \% \mathrm{Cl}: 0.91-1.15$ ); AA vs GA: (OR = 0.99, 95\%Cl: 0.89-1.10); recessive model: (OR: 1.03, 95\%Cl: 0.94-1.13); dominant model: (OR: $1.00,95 \% \mathrm{Cl}: 0.90-1.10)$ (27). No confounding effect of ethnicity was shown, since the stratified analysis either in Asians or Caucasians showed no significant association (27). Two later studies have shown an increased risk of BC in patients carrying the A-allele of VEGFA $2578 \mathrm{C} / \mathrm{A}$ gene polymorphism $(28,29)$. An increased risk of BC was observed in patients carrying the VEGFA 2578 A-allele $(28,29)$ and in patients with VEGFA 2578 AA genotype (OR: 2.87; 95\%Cl, 1.61-5.10; $\mathrm{p}=0.0003$ ) and A-allele (OR: $1.65 ; 95 \% \mathrm{Cl}: 1.25-2.18 ; \mathrm{p}=0.0004$ ) in 204 cases and controls from North India (28). The same result was observed in an Iranian study encompassing 250 cases and 215 controls (29). The VEGFA 2578 C/A variant increased the risk of BC: CA vs CC (OR: 1.71; 95\%Cl: 1.15-2.54; $p=0.009 ;$ AA vs CC (OR: $2.12,95 \% \mathrm{Cl}: 1.14-3.93 ; p=0.021) ; C A+A A$ vs CC (OR: $1.78,95 \% \mathrm{Cl}: 1.22-2.60 ; p=0.004)$; A vs C (OR: $1.47,95 \% \mathrm{Cl}: 1.12-1.92, p=0.005)$ (29). Although our results are similar to the meta-analysis with a large sample size, perhaps a new meta-analysis including the three new studies could throw some light into the association of VEGFA 2578 polymorphism with BC risk.

Regarding the effect of VEGFA 2578 C/A polymorphism on DFS of BC patients, we could not confirm the association shown by the studies by Maae et al. 2012 (25) and SaNguanraksa et al. 2013 (26), performed in Caucasians and Thais populations, respectively. The VEGFA 2578 polymorphism did not present an association with DFS either in 581 Brazilian BC patients treated with curative surgery (30). However, patients carrying the A-allele of the VEGFA 2578 C/A polymorphism had shorter DFS among when treated with neoadjuvant chemotherapy followed by mastectomy (309 patients) (HR: 
1.82; $95 \% \mathrm{Cl}=1.16-2.86)(30)$. While no association was found between VEGFA 2578 C/A polymorphism and DFS in 441 Caucasian BC patients, neither in the univariate regression analysis or after adjusting with clinical characteristics, an increased risk of BC recurrence was showed for the haplotype formed by VEGFA 2578 C, rs1570360 G and $634 \mathrm{G}$ (HR: 1.58, 95\% Cl: 1.06-2.35; $\mathrm{p}=0.03$ ) (31). There is some controversy about the meaning of the $C$ allele. While Kidd et al. showed that the negative effect on $B C$ recurrence is due to the VEGFA 2578 C-allele in the haplotype, the results of the univariate and multivariate analysis did not correlate with this effect. The VEGFA 2578 A-allele was related to lower DFS, but only in the group of patients treated with neoadjuvant treatment, not in the patients treated with surgery. This difference appeared to be due to a lower risk of progression in comparison with the neoadjuvant chemotherapy sub-cohort. Only $7.1 \%$ of our patients received neoadjuvant treatment; for this reason, these studies could not be compared.

In our study, patients carrying the A-allele for VEGFA $2578 \mathrm{C}>\mathrm{A}$ tended to longer OS compared to CC patients (CC vs A-allele HR: 2.08; $\mathrm{Cl}_{95 \%}=0.96-4.49 ; \mathrm{p}$ value $=0.0587$ ) (Table 5, Figures S1 and S2). No association was either shown in the only other study published to date investigating the influence of VEGFA $2578 \mathrm{C}>\mathrm{A}$ polymorphism on OS in 441 Caucasian women (31).

The VEFGA 7C>T polymorphism was not been associated with BC risk in our study. This result is similar to those previously published in an English cohort with 490 cases and 493 controls and in a North Indian population with 204 cases and controls, respectively $(28,32)$.

Our study failed to confirm the association between the VEFGA 7C>T polymorphism and DFS as reported in a study of 116 HER2-positive BC patients treated with trastuzumab (DFS CC vs T-allele; $p=0.070$ ) (25).

In our study, the VEGFA 7C>T polymorphism has not been associated to OS. Although a previous study suggested this influence in a cohort of 328 BC patients $(p=0.027)$, that result should be considered carefully, since no correction for multiple testing was applied (32).

The main limitation of this study was the limited size of the sample compared to other studies, particularly in the cases group. This may have led to a lack of power to detect associations in some polymorphisms and in clinical variables such as the stage and OS. 
The strengths of our study include a very homogeneous cohort of cases, only composed by $B C$ patients diagnosed by the same team of pathologists, recruited from the same geographic area, which increases their uniformity.

In summary, we investigated the effect of ABCB1-G1199T/A (rs2229109), VEGFA 634 G>C (rs2010963), VEGFA 2578 C>A (699947) and VEGFA 7 C>T (rs25648) gene polymorphisms on $\mathrm{BC}$ risk and prognosis. The results showed no association between these gene polymorphisms and susceptibility of $B C$, suggesting that genetic variations in genes involved in drug transporters and angiogenesis may not influence the risk or outcomes of BC.

\section{CONCLUSIONS}

No influence ABCB1-G1199T/A (rs2229109), VEGFA -634 G>C (rs2010963), VEGFA 2578 C>A (rs699947) and VEGFA 7 C>T (rs25648) on risk of BC was found in our study. There was no association between the polymorphisms studied and DFS and OS. Further studies including a wider spectrum of gene polymorphisms and larger sample cohorts will be required to definitely rule out the influence of these genes on risk of $B C$, DFS and OS.

\section{FIGURE LEGENDS}

Figure S1. Overall Survival in breast cancer patients according to VEGFA rs699947 genotype.

Figure S2. Overall Survival in breast cancer patients according to VEGFA rs699947 Aallele and CC genotype.

Figure S3. Disease Free Survival in breast cancer patients according to ABCB1-rs2229109 A-allele and GG genotype.

\section{ACKNOWLEDGMENTS}

The results of this investigation are part of the doctoral thesis presented by Adela Madrid-Paredes at the University of Granada, within the Doctoral Program in Pharmacy.

\section{CONFLICT OF INTEREST}

The authors declare that there is no conflict of interest that could be perceived as prejudicing the impartiality of the research reported, and that there are no competing financial interests in relation to the work described in this article. 


\section{REFERENCES}

1. WHO. OMS | Cáncer de mama: prevención y control. WHO. World Health Organization.

2. Perou CM, Sørlie T, Eisen MB, van de Rijn M, Jeffrey SS, Rees CA, et al. Molecular portraits of human breast tumours. Nature. 2000 Aug 17;406(6797):747-52.

3. Turgut S, Yaren A, Kursunluoglu R, Turgut G. MDR1 C3435T polymorphism in patients with breast cancer. Arch Med Res. 2007 Jul;38(5):539-44.

4. Kataoka N, Cai Q, Wen W, Shu XO, Jin F, Gao Y-T, et al. Population-based casecontrol study of VEGF gene polymorphisms and breast cancer risk among Chinese women. Cancer Epidemiol Biomarkers Prev. 2006 Jun;15(6):1148-52.

5. Zhou S-F. Structure, function and regulation of P-glycoprotein and its clinical relevance in drug disposition. Xenobiotica. $2008 \mathrm{Jul} ; 38(7-8): 802-32$.

6. Leonessa F, Clarke R. ATP binding cassette transporters and drug resistance in breast cancer. Endocr Relat Cancer. 2003 Mar;10(1):43-73.

7. Brambila-Tapia AJ-L. MDR1 (ABCB1) polymorphisms: functional effects and clinical implications. Rev Invest Clin. 2013 Sep;65(5):445-54.

8. Wang Z, Wang T, Bian J. Association between MDR1 C3435T polymorphism and risk of breast cancer. Gene. 2013 Dec 10;532(1):94-9.

9. Abuhaliema AM, Yousef A-MF, El-Madany NN, Bulatova NR, Awwad NM, Yousef MA, et al. Influence of Genotype and Haplotype of MDR1 (C3435T, G2677A/T, C1236T) on the Incidence of Breast Cancer--a Case-Control Study in Jordan. Asian Pacific Journal of Cancer Prevention. 2016;17(1):261-6.

10. Wu H, Kang $H$, Liu $Y$, Tong $W$, Liu $D$, Yang $X$, et al. Roles of ABCB1 gene polymorphisms and haplotype in susceptibility to breast carcinoma risk and clinical outcomes. J Cancer Res Clin Oncol [Internet]. 2012 Sep;138(9):1449-62. 
11. Sainz J, Rudolph A, Hein R, Hoffmeister M, Buch S, Schönfels von W, et al. Association of genetic polymorphisms in ESR2, HSD17B1, ABCB1, and SHBG genes with colorectal cancer risk. Endocr Relat Cancer. 2011 Apr;18(2):265-76.

12. Jakobsen Falk I, Lund J, Gréen H, Gruber A, Alici E, Lauri B, et al. Pharmacogenetic study of the impact of $A B C B 1$ single-nucleotide polymorphisms on lenalidomide treatment outcomes in patients with multiple myeloma: results from a phase IV observational study and subsequent phase II clinical trial. Cancer Chemother Pharmacol. 2018 Jan;81(1):183-93.

13. Björn N, Falk IJ, Vergote I, Gréen H. ABCB1 Variation Affects Myelosuppression, Progression-free Survival and Overall Survival in Paclitaxel/Carboplatin-treated Ovarian Cancer Patients. Basic Clin Pharmacol Toxicol. 2018 Mar 5.

14. Gréen H, Söderkvist $P$, Rosenberg P, Horvath G, Peterson C. ABCB1 G1199A polymorphism and ovarian cancer response to paclitaxel. J Pharm Sci. 2008 Jun;97(6):2045-8.

15. Makrilia N, Lappa T, Xyla V, Nikolaidis I, Syrigos K. The role of angiogenesis in solid tumours: an overview. Eur J Intern Med. 2009 Nov;20(7):663-71.

16. Kerbel RS. Tumor angiogenesis. N Engl J Med. 2008 May 8;358(19):2039-49.

17. Niu G, Chen X. Vascular endothelial growth factor as an anti-angiogenic target for cancer therapy. Curr Drug Targets. 2010 Aug;11(8):1000-17.

18. Jakubowska A, Gronwald J, Menkiszak J, Górski B, Huzarski T, Byrski T, et al. The VEGF_936_C>T 3'UTR polymorphism reduces BRCA1-associated breast cancer risk in Polish women. Cancer Lett. 2008 Apr 8;262(1):71-6.

19. Koutras A, Kotoula V, Fountzilas G. Prognostic and predictive role of vascular endothelial growth factor polymorphisms in breast cancer. Pharmacogenomics. 2015 Jan;16(1):79-94.

20. Watson CJ, Webb NJ, Bottomley MJ, Brenchley PE. Identification of polymorphisms within the vascular endothelial growth factor (VEGF) gene: 
correlation with variation in VEGF protein production. Cytokine. 2000 Aug;12(8):1232-5.

21. Liu L, Liu L, Zeng F, Wang K, Huang J, Xin L, et al. Meta-analysis of the association between VEGF-634 G>C and risk of malignancy based on 23 case-control studies. J Cancer Res Clin Oncol. 2011 Jun;137(6):1027-36.

22. Yao W, Yan R, Ma L, Wan H, Yu Y, Cheng X, et al. Vascular endothelial growth factor gene polymorphism (-634G/C) and breast cancer risk. Tumour Biol. 2014 May 10;35(8):7793-8.

23. Rahoui J, Laraqui A, Sbitti Y, Touil N, Ibrahimi A, Ghrab B, et al. Investigating the association of vascular endothelial growth factor polymorphisms with breast cancer: a Moroccan case-control study. Med Oncol. 2014 Sep;31(9):193.

24. Ma J, Hu W, Zhang P, Sun Y, Wang N, Teng X, et al. The Association Between VEGF +936C/T and -634G/C Polymorphisms and Breast Cancer Susceptibility, Tumor Growth, and Metastases: Evidence From 20,728 Subjects. Cancer Invest. 2015;33(7):312-7.

25. Maae E, Andersen RF, Steffensen KD, Jakobsen EH, Brandslund I, Sørensen FB, et al. Prognostic impact of VEGFA germline polymorphisms in patients with HER2positive primary breast cancer. Anticancer Res. 2012 Sep;32(9):3619-27.

26. Sa-Nguanraksa D, Chuangsuwanich T, Pongpruttipan T, Kummalue T, Rojananin S, Ratanawichhitrasin A, et al. Vascular endothelial growth factor 634G/C polymorphism is associated with increased breast cancer risk and aggressiveness. Mol Med Rep. 2013 Oct;8(4):1242-50.

27. Zhang Y, Yu YF, Wang JZ, Jia H. Vascular endothelial growth factor $+405 \mathrm{G} / \mathrm{C}$ and 2578C/A polymorphisms and breast cancer risk: a meta-analysis. Genet Mol Res. 2015 Aug 3;14(3):8909-18. 
28. Kapahi R, Guleria K, Sambyal V, Manjari M, Sudan M, Uppal MS, et al. Association of VEGF and VEGFR1 polymorphisms with breast cancer risk in North Indians. Tumour Biol. 2015 Jun;36(6):4223-34.

29. Rezaei M, Hashemi M, Sanaei S, Mashhadi MA, Taheri M. Association Between Vascular Endothelial Growth Factor Gene Polymorphisms with Breast Cancer Risk in an Iranian Population. BCBCR. 2016;10:85-91.

30. Vieira-Monteiro H de A, Freitas-Alves DR, Sobral-Leite M, Delou JM de A, GoulartCitrangulo SMT, do Nascimento CT, et al. Prognostic evaluation of VEGFA genotypes and haplotypes in a cohort of Brazilian women with non metastatic breast cancer. Cancer Biol Ther. 2016 Jun 2;17(6):674-83.

31. Kidd LR, Brock GN, VanCleave TT, Benford ML, Lavender NA, Kruer TL, et al. Angiogenesis-associated sequence variants relative to breast cancer recurrence and survival. Cancer Causes Control. 2010 Oct;21(10):1545-57.

32. Balasubramanian SP, Cox A, Cross SS, Higham SE, Brown NJ, Reed MW. Influence of VEGF-A gene variation and protein levels in breast cancer susceptibility and severity. Int J Cancer. 2007 Sep 1;121(5):1009-16.

33. Edge SB, Compton CC. The American Joint Committee on Cancer: the 7th edition of the AJCC cancer staging manual and the future of TNM. Ann Surg Oncol. 2010 Jun;17(6):1471-4.

34. Jiménez-Varo E, Cañadas-Garre M, Henriques $\mathrm{Cl}$, Pinheiro AM, Gutiérrez-Pimentel MJ, Calleja-Hernández MÁ. Pharmacogenetics role in the safety of acenocoumarol therapy. Thromb Haemost. 2014 Sep 2;112(3):522-36.

35. Team RC. R: A language and environment for statistical computing. [Internet]. 2013 Oct. Available from: http://www.R-project.org/

36. Purcell S, Neale B, Todd-Brown K, Thomas L, Ferreira MAR, Bender D, et al. PLINK: a tool set for whole-genome association and population-based linkage analyses. Am J Hum Genet. 2007 Sep;81(3):559-75. 